Article (refereed)

Mercado, Lina M.; Bellouin, Nicolas; Sitch, Stephen; Boucher, Olivier; Huntingford, Chris; Wild, Martin; Cox, Peter M.. 2009 Impact of changes in diffuse radiation on the global land carbon sink. Nature, 458. 1014-1017. $10.1038 /$ nature07949

(C) 2009 Macmillan Publishers Limited

This version available at http://nora.nerc.ac.uk/6771/

NERC has developed NORA to enable users to access research outputs wholly or partially funded by NERC. Copyright and other rights for material on this site are retained by the authors and/or other rights owners. Users should read the terms and conditions of use of this material at http://nora.nerc.ac.uk/policies.html\#access

This document is the author's final manuscript version of the journal article, incorporating any revisions agreed during the peer review process. Some differences between this and the publisher's version remain. You are advised to consult the publisher's version if you wish to cite from this article. www.nature.com 


\section{Impact of Changes in Diffuse Radiation on the Global Land Carbon Sink}

Lina M. Mercado ${ }^{1}$, Nicolas Bellouin ${ }^{2}$, Stephen Sitch $^{2}$, Olivier Boucher ${ }^{2}$, Chris Huntingford ${ }^{1}$, Martin Wild ${ }^{3}$ and Peter M. Cox ${ }^{4}$

${ }^{1}$ Centre for Ecology and Hydrology, Wallingford, Oxon OX10 8BB, UK

${ }^{2}$ Met Office Hadley Centre, Exeter, EXI 3PB, UK

${ }^{3}$ ETH Zurich, Institute for Atmospheric and Climate Science, CH 8092 Zurich, Switzerland

${ }^{4}$ School of Engineering, Computer Science and Mathematics, University of Exeter, EX4 4QF, UK

Plant photosynthesis tends to increase with irradiance. However, recent theoretical and observational studies have demonstrated that photosynthesis is also more efficient under diffuse light conditions ${ }^{1-5}$. Changes in cloud cover or atmospheric aerosol loadings, arising from either volcanic or anthropogenic emissions, alter both the total Photosynthetically Active Radiation (PAR) reaching the surface and the fraction of this radiation which is diffuse, with uncertain overall effects on global plant productivity and the land carbon sink. Here we estimate for the first time, the impact of variations in diffuse fraction on the land carbon sink using a global model modified to account for the effects of variations in both direct and diffuse radiation on canopy photosynthesis. We estimate that variations in diffuse fraction, associated largely with the "global dimming" period $^{6-8}$, enhanced the land carbon sink by approximately a quarter 
from 1960 to 1999 . However, under a climate mitigation scenario for the $21^{\text {st }}$ century in which sulphate aerosols decline before atmospheric $\mathrm{CO}_{2}$ is stabilised, this "diffuse-radiation" fertilisation effect declines rapidly to near zero by the end of the $21^{\text {st }}$ century.

The solar radiation reaching the Earth's surface is the primary driver of plant photosynthesis. Leaf photosynthesis increases non-linearly with incident PAR, saturating at light levels which are often exceeded on bright days during the growing season (Fig 1). In clear-sky conditions, a fraction of the plant canopy is illuminated by direct solar radiation consisting of bright "sunflecks", with the remaining portion of the canopy being in the shade. The sunlit fraction of the canopy has leaves which are often light saturated and therefore have low light use efficiency, while leaves in the shade are more light-use efficient but suffer from a lower exposure to incoming radiation. In contrast, under cloudy or sulphate-aerosol-laden skies, sunlight is more scattered and incoming radiation is more diffuse producing a more uniform irradiance of the canopy with a smaller fraction of the canopy likely to be light-saturated. As a result, canopy photosynthesis tends to be significantly more light-use efficient under diffuse rather than direct sunlight ${ }^{3}$. Hence, the net effect on photosynthesis of radiation changes associated with an increase in clouds or scattering aerosols depends on a balance between the reduction in the overall total PAR (which tends to reduce photosynthesis) and the increase in the diffuse fraction of the PAR (which tends to increase photosynthesis). While some global climate-carbon cycle models include the effects of atmospheric aerosols on total irradiance and surface temperature (e.g. ref. 9), none has accounted for the effects of clouds and aerosols on the land carbon sink via changes in the diffuse fraction of radiation. 
To account for the effects of diffuse radiation on canopy photosynthesis, we modified the JULES land surface scheme used in the Hadley Centre climate models ${ }^{10}$. JULES includes a multilayer approach to scale photosynthesis from the leaf to the canopy. In this study we also separated each canopy layer into sunlit and shaded regions ${ }^{11}$. Figure 1 shows a comparison of the simulated light response of Gross Primary Productivity (GPP) against measurements inferred from the eddy correlation technique under direct and diffuse irradiance conditions within a broadleaf ${ }^{12}$ and a needleleaf temperate forest ${ }^{13}$. The modified JULES model is able to reproduce the different light response curves under diffuse and direct radiation within the error bars of the observations. A sensitivity analysis carried out for the broadleaf forest shows that simulated GPP reaches a maximum at a diffuse fraction of 0.4 after which GPP decreases due to a reduction in the total PAR (Fig S1).The existence of such an optimum is in agreement with a previous modelling study for the same site ${ }^{14}$.

We performed multiple global simulations with JULES over the period 1901 to 2100 to assess the impact of changing diffuse radiation on the global land carbon sink. For 1901 to 1999, we used an observed monthly climatology of the main climate variables ${ }^{15}$, except direct and diffuse total shortwave and PAR fluxes which were reconstructed using radiative transfer calculations. The reconstruction takes into account the scattering and absorption of solar radiation by tropospheric aerosols as simulated by the Hadley Centre Global Environmental Model (version HadGEM2-A) ${ }^{16}$, a climatology of stratospheric aerosols ${ }^{17}$ and a cloudiness dataset $^{15}$ (see methodology). For the period 2000 to 2100 we prescribed varying atmospheric $\mathrm{CO}_{2}$ concentration and monthly fields of anthropogenic aerosols, following an A1B $450 \mathrm{ppm}$ $\mathrm{CO}_{2}$ equivalent stabilization scenario relying on the A1B storyline and the methodology from ref. 18. Under this scenario, diffuse fraction increases during the second half of the $20^{\text {th }}$ century and then decreases during the $21^{\text {st }}$ century due to correspondingly increasing and decreasing 
anthropogenic aerosols emissions (Figs 3a and 4a). The uncertain effects of future changes in climate were not considered so as to isolate the diffuse radiation effect.

Aerosols also have indirect effects on total PAR through modifying cloud properties, although these effects are more uncertain ${ }^{19}$.To provide an upper estimate of the impact of the first indirect effect (i.e. the effect of aerosols on cloud brightness) on the land biosphere ${ }^{20}$ we assume an absolute reduction in PAR beneath clouds equal to the absolute reduction in clearsky PAR due to aerosols ${ }^{19}$. A "fixed diffuse fraction" control simulation was performed by prescribing the mean diffuse fraction for each gridbox and month, based on our reconstruction of the period 1901-1910. The remaining climatological variables in this simulation (including total PAR) varied as in the first simulation, enabling us to isolate the effect of the varying diffuse fraction as the difference between these two model runs. (See online methods and Supplementary Information for a description of other sensitivity tests undertaken.)

The eruption of Mount Pinatubo in 1991 provided a natural test of the impact of a large increase in stratospheric aerosol loading on the land carbon cycle. The main climatic consequences of the eruption were a cooling of the surface due to scattering aerosols, and an anomalously low growth rate of the atmospheric $\mathrm{CO}_{2}$ concentration in both 1992 and 1993, due to an enhanced terrestrial carbon $\operatorname{sink}^{21,22}$. Several explanations have been proposed to explain this anomalous land sink, including suppression of plant and heterotrophic respiration during the relatively cool summers ${ }^{23,24}$ and enhanced canopy photosynthesis as a result of the postPinatubo increase in diffuse fraction ${ }^{2,3}$. However, the relative contributions of these processes during the post-Pinatubo years of 1992 and 1993, and their spatial distribution, remain uncertain. 


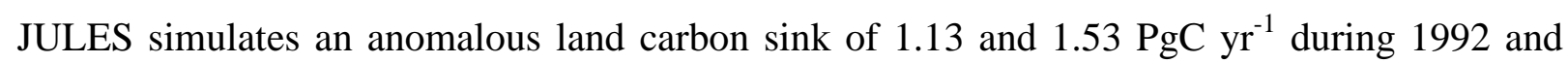
1993 respectively, in general agreement with the land flux inferred from observations ${ }^{22,25}$ (Fig. 2). Our model suggest a major contribution of diffuse radiation to the land sink anomaly in

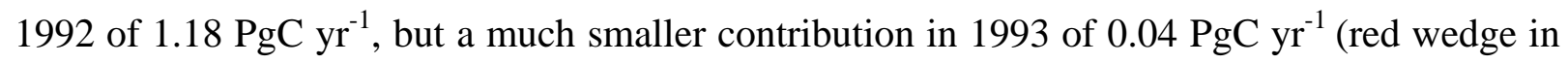

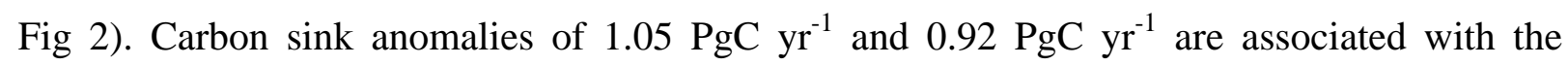
anomalously cool air temperatures in 1992 and 1993 (anomalies of $-0.33 \mathrm{~K}$ and $-0.21 \mathrm{~K}$ ) which act to suppress heterotrophic respiration (for further details see Figs. S2-S5).

A decrease in total solar radiation ${ }^{6-8}$ has been observed at the Earth's surface over the 19501980 period, termed "global dimming". This decrease is consistent with the impacts of anthropogenic aerosols on cloud properties, water vapour and cloud feedbacks due to global warming $^{26}$. Increases in cloud thickness, cloud cover and scattering aerosols enhance the diffuse component of radiation reaching the surface while increasing absorbing aerosols can have the opposite effect ${ }^{27}$. As a result observed trends in diffuse radiation are not as coherent as those in total radiation during the dimming period ${ }^{28-30}$. Since the 1980 s industrialised regions of the Northern Hemisphere appear to have "brightened", associated with reduced anthropogenic emissions of aerosol precursors (especially sulphur dioxide) in these regions.

Figure 3 a shows changes in the diffuse fraction of PAR as reconstructed using cloud cover ${ }^{14}$ and aerosol distributions. The simulated total shortwave radiation and diffuse fraction compare well against ground based radiation measurements (Figs. S6 and S7). The contribution of variations in diffuse fraction to the simulated land carbon sink, becomes important after 1950 (Fig. 3b). This contribution increases during the global dimming period (1960-1980) when it

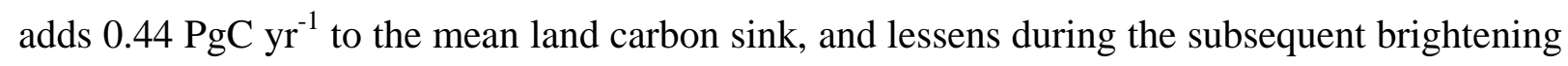
period (1980-1999) when it contributes a mean of $0.3{\mathrm{PgC} \mathrm{yr}^{-1}}$, as a result of decreasing diffuse fraction. 
The HadGEM2-A reconstruction suggests geographically varying changes in diffuse fraction of $-5 \%$ to $30 \%$ from 1950 to 1980 (Fig. 3c). The corresponding impact on the regional land sink is estimated to be large, reaching up to $30 \mathrm{gC} \mathrm{m}^{-2} \mathrm{yr}^{-1}$ across Europe, Eastern United States, East Asia and some tropical regions in Africa (Fig. 3d). In contrast, during the brightening period 1980-2000 (Fig. S8), the HadGEM2-A reconstruction suggests a reduction in diffuse fraction over Europe, Eastern USA, Western Australia and some regions of Russia and China, leading to a reduction in the regional contribution of the diffuse fraction to the total land carbon accumulation over this period. Overall these results suggest that increases in diffuse fraction have enhanced the global land carbon sink by $23.7 \%$ from 1960 to 1999 (Fig. 4b). As shown in Fig. S9, the contributions of diffuse fraction to the land sink are of similar magnitude to the net contributions of variations in temperature and precipitation over this period.

Neglecting "diffuse-radiation fertilization", as in the current generation of global models, we estimate that reductions in total PAR would have caused a $-14.4 \%$ change in the mean land carbon sink. Instead we model a net enhancement of the land carbon sink by overall (diffuse and direct) radiation changes of $+9.3 \%$, as diffuse radiation fertilization overwhelms "global dimming" (see Fig S10 for regional contributions to GPP). Contrary to the results of current global models, it therefore seems that anthropogenic aerosols have enhanced land carbon uptake over this period despite significant reductions in total PAR. Fully coupled Earth system model simulations are now required to confirm this result when accounting for the effects of short timescale variability in atmospheric aerosol loading.

To project these results into the $21^{\text {st }}$ century an environmentally friendly emissions scenario (ENSEMBLES A1B-450) was assumed, in which total greenhouse gas concentrations stabilize 
at $450 \mathrm{ppmv} \mathrm{CO}_{2}$ equivalent, and sulphate and black carbon aerosol emissions decline rapidly. Under this scenario atmospheric carbon dioxide peaks at 435 ppmv around 2050 before declining steadily to reach 421 ppmv by 2100 . The total aerosol optical depth declines steeply from its 2000 maximum of 0.12 and levels off at 0.10 by 2050 (Fig. 4a). As a result, the HadGEM2-A reconstruction suggests a rapid reduction in the diffuse fraction of PAR, which leads to a rapid decline in the contribution of diffuse radiation to the land carbon sink. By 2100 , diffuse-radiation fertilization is lost (Fig. 4b). We conclude that steeper cuts in fossil fuel emissions will be required to stabilize the climate if anthropogenic aerosols decline as expected.

\section{Methods Summary}

This study uses the JULES land surface scheme ${ }^{10}$ which takes into account variations of direct and diffuse radiation on sunlit and shaded canopy photosynthesis. We added a description of sunfleck penetration through the canopy ${ }^{11}$ and separated each layer of the canopy into sunlit and shaded regions. In this way, photosynthesis of sunlit and shaded leaves is calculated separately assuming that shaded leaves receive only diffuse light and sunlit leaves receive both diffuse and direct radiation.

The geographical distributions of the downward direct and diffuse radiative fluxes throughout the $20^{\text {th }}$ and $21^{\text {st }}$ centuries were obtained by coupling distributions of clouds and aerosols (tropospheric and stratospheric ${ }^{17}$ ) using look-up tables of radiative transfer calculations. Distributions of aerosol optical depths (AOD) at $0.55 \mu \mathrm{m}$ for six tropospheric aerosol species for the $20^{\text {th }}$ century were taken from simulations of HadGEM2-A, the atmospheric version of the latest Hadley Centre Global Environmental Model. AOD distributions for sulphate and black-carbon in the $21^{\text {st }}$ century were obtained by scaling the distributions for the year 2000 according to changes in ammonium sulphate burden obtained using the ENSEMBLES A1B 
450 scenario relying on the A1B storyline and the methodology from ref. 18 . The four other tropospheric aerosol species, and stratospheric aerosols, were left unchanged at their 2000 levels because their future evolutions are uncertain.

This study uses the $0.5^{\circ}$ resolution observed monthly climatology ${ }^{15}$. All monthly data were regridded onto a $2.75^{\circ} \times 3.75^{\circ}$ grid and disaggregated to hourly data. Future climate change for the $21^{\text {st }}$ century was not considered, and climate variables, including cloud cover, were taken as fixed at their year 1999 values throughout the $21^{\text {st }}$ century simulation.

In each case percentage changes in the land carbon sink are calculated relative to our "fixed diffuse fraction" control simulation. 


\section{References}

1 Goudriaan, J. Crop micrometeorology: A simulation study. Centre for Agricultural Publishing and Documentation, Wageningen. (1977).

2 Gu, L. H. et al. Response of a deciduous forest to the Mount Pinatubo eruption: Enhanced photosynthesis. Science 299, 2035-2038 (2003).

3 Roderick, M. L., Farquhar, G. D., Berry, S. L. \& Noble, I. R. On the direct effect of clouds and atmospheric particles on the productivity and structure of vegetation. Oecologia 129, 21-30 (2001). Niyogi, D. et al. Direct observations of the effects of aerosol loading on net ecosystem $\mathrm{CO} 2$ exchanges over different landscapes. Geophys. Res. Lett.31, doi: 10.1029/2004G1020915 (2004).

Oliveira, P. H. F. et al. The effects of biomass burning aerosols and clouds on the $\mathrm{CO}_{2}$ flux in Amazonia. Tellus B. 59, 338-349, doi:10.1111/J.16000889.2007.00270 (2007).

Stanhill, G. \& Cohen, S. Global dimming: a review of the evidence for a widespread and significant reduction in global radiation with discussion of its probable causes and possible agricultural consequences. Agric. For. Meteorol. 107, 255-278 (2001).

7 Liepert, B. G. Observed reductions of surface solar radiation at sites in the United States and worldwide from 1961 to 1990. Geophys. Res. Lett. 29, doi:10.1029/2002G1014910 (2002). Wild, M. et al. From dimming to brightening: Decadal changes in solar radiation at Earth's surface. Science 308, 847-850 (2005). 
Jones, C. D., Cox, P. M., Essery, R. L. H., Roberts, D. L. \& Woodage, M. J. Strong carbon cycle feedbacks in a climate model with interactive $\mathrm{CO}_{2}$ and sulphate aerosols. Geophys. Res. Lett. 30, doi:10.1029/2003G1016867 (2003). Mercado, L. M., Huntingford, C., Gash, J. H. C., Cox, P. M. \& Jogireddy, V. Improving the representation of radiation interception and photosynthesis for climate model applications. Tellus B. 59, 553-565 (2007). Dai, Y. J., Dickinson, R. E. \& Wang, Y. P. A two-big-leaf model for canopy temperature, photosynthesis, and stomatal conductance. J. Clim. 17, 22812299 (2004).

Knohl, A., Schulze, E. D., Kolle, O. \& Buchmann, N. Large carbon uptake by an unmanaged 250-year-old deciduous forest in Central Germany. Agric. For. Meteorol. 118, 151-167 (2003).

Rebmann, C. et al. Influence of transport processes on CO2-exchange at a complex forest site in Thuringia, Germany. Agric. For. Meteorol. Submitted (2008).

Knohl, A. \& Baldocchi, D. D. Effects of diffuse radiation on canopy gas exchange processes in a forest ecosystem. J. Geophys. Res. 113, doi:10.1029/2007JG000663 (2008). New, M., Hulme, M. \& Jones, P. Representing twentieth-century space-time climate variability. Part II: Development of 1901-96 monthly grids of terrestrial surface climate. J. Clim. 13, 2217-2238 (2000). Bellouin, N. Improved representation of aerosols for HadGEM2. Met Office Hadley Centre Technical Note 73 available at http://www.metoffice.gov.uk/ research/hadleycentre/pubs/HCTN/index.html (2007). 
Sato, M., Hansen, J., McCormick , M. \& Pollack, J. Stratospheric Aerosol Optical Depths, 1850-1990. J. Geophys. Res. 98, 22987-22994 (1993). van Vuuren, D. P. et al. Stabilizing greenhouse gas concentrations at low levels: an assessment of reduction strategies and costs. Climatic Change 81, 119-159, doi:10.1007/S10584-006-9172-9 (2007).

Forster, P. et al. in Climate Change 2007: The Physical Science Basis (eds Solomon, S. et al.) 129-234 (Cambridge Univ. Press, Cambridge, UK, 2007).

Gu, L., Fuentes, J. D., Shugart, H. H., Staebler, R. M. \& Black, T. A. Responses of net ecosystem exchanges of carbon dioxide to changes in cloudiness: results from two North American deciduous forests. J. Geophys. Res. 104, 31421-31434 (1999). Ciais, P., Tans, P. P., Trolier, M., White, J. W. C. \& Francey, R. J. A large northern-hemisphere terrestrial $\mathrm{CO}_{2}$ sink indicated by the $\mathrm{C}-13 / \mathrm{C}-12$ ratio of atmospheric $\mathrm{CO}_{2}$. Science 269, 1098-1102 (1995).

Keeling, C. D., Whorf, T. P., Wahlen, M. \& Vanderplicht, J. Interannual extremes in the rate of rise of atmospheric carbon-dioxide since 1980. Nature 375, 666-670 (1995).

Lucht, W. et al. Climatic control of the high-latitude vegetation greening trend and Pinatubo effect. Science 296, 1687-1689 (2002).

Jones, C. D. \& Cox, P. M. Modeling the volcanic signal in the atmospheric $\mathrm{CO}_{2}$ record. Glob. Biogeochem. Cycle 15, 453-465 (2001).

Buitenhuis, E. et al. Biogeochemical fluxes through mesozooplankton. Glob. Biogeochem. Cycle 20, doi: 10.1029/2005GB002511 (2006). 
Romanou, A. et al. 20th century changes in surface solar irradiance in simulations and observations. Geophys. Res. Lett.34, doi:10.1029/2006GL028356 (2007). Liepert, B. \& Tegen, I. Multidecadal solar radiation trends in the United States and Germany and direct tropospheric aerosol forcing. J. Geophys. Res. 107, doi:10.1029/2001JD000760 (2002). Power, H. C. Trends in solar radiation over Germany and an assessment of the role of aerosols and sunshine duration. Theor. Appl. Climatol. 75, 47-63 (2003).

Russak, V. Changes in solar radiation and their influence on temperature trend in Estonia (1955-2007). J. Geophys. Res. Submitted (2008). Investigations of Surface Downwelling Solar Radiation for the Continental US. J. Geophys. Res. Submitted (2008).

Acknowledgements. We thank A. Knohl and C. Rebmann for supplying the eddy flux data for model evaluation, D. van Vuuren and the group that developed the IMAGE model for providing scenario data for the $21^{\text {st }}$ century simulation. We also thank C.D. Jones for advice on the experimental design, C.M. Taylor for discussions on early results, R. Ellis and P. Harris for both scientific and technical support, A. Everitt for computer support, and G. Weedon for useful discussions. The Authors acknowledge funding from the UK National Environment Research Council -CLASSIC programme (L.M.M, C.H and P.M.C); the UK Department for Environment, Food and Rural Affairs and the UK Ministry of Defence (N.B, O.B and S.S) under (Defra) GA01101, (MoD) CBC/2B/0417_Annex C5. 
Author contributions L.M.M. and P.M.C. developed the modification of the JULES model to include sunfleck penetration through the canopy. L.M.M. validated the model at site level, analysed and performed the global simulations and wrote the initial version of the manuscript. O.B. and N.B. developed the framework for producing the shortwave and PAR fields. N.B. developed the look up tables to reconstruct shortwave and PAR fields in clear- and cloudy-sky and validated the output against ground based observations. O.B. provided the sulphate aerosol burden for the $21^{\text {st }}$ century. P.M.C. had a major contribution throughout the study, and S.S to the analysis of results. C.H developed the IMOGEN software that enables the global simulations to be carried out. M.W. provided ground based observations of shortwave and diffuse radiation time series and also advised on model validation. All authors discussed the results, structure of the paper, developed and improved the manuscript.

Author information The authors declare no competing financial interests. Correspondence and request for material should be addressed to L.M.M (lmme@ceh.ac.uk). 
Figure 1. JULES model evaluation against observations. Observed and modelled light response of Gross Primary Productivity (GPP) to both direct and diffuse PAR (open triangle and closed circles, respectively) averaged over $200 \mu \mathrm{mol}$ quanta $\mathrm{m}^{-2} \mathrm{~s}^{-1}$ bins. For the purposes of this validation data points are split into "diffuse" and "direct" conditions, using diffuse fractions of greater than $80 \%$ and less than $25 \%$ to discriminate these two cases. Measurements inferred from eddy correlation are given in black (error bars represent one standard deviation), and simulations are given in pink (see methods). The left-hand panel represents measurements and simulations for a broadleaf forest site, and the right-hand panel is for a needleleaf forest site.

Figure 2. Observed and simulated detrended anomalies of Net Ecosystem Exchange (NEE) for 1980 to 1999. Inferred NEE values (derived from atmospheric $\mathrm{CO}_{2}$ measurements ${ }^{21}$ and simulated ocean flux ${ }^{25}$ ) are shown by the green line in the top panel. Also presented are simulated global detrended flux anomalies of NEE (black) under varying (continuous line) and fixed (dashed line) diffuse fraction. The red shaded area corresponds to the contribution of the varying diffuse fraction to simulated NEE, calculated as the difference between the fluxes simulated under conditions of varying and fixed diffuse fraction. NEE is defined as the difference between net primary productivity (NPP) and heterotrophic respiration (RH). Vertical lines in the upper panel correspond to the timing of El Chichón and Pinatubo volcanic eruptions, respectively. The lower panel presents the simulated NPP values for varying (continuous line) and fixed (dashed line) diffuse fraction, with the red shaded area again corresponding to the contribution of varying diffuse irradiance to simulated NPP.

Figure 3. Impact of changes in diffuse fraction on the land carbon sink over the 20th century. a. Simulated global mean annual diffuse fraction of PAR, based on aerosol optical 
depth from volcanic ${ }^{17}$ and anthropogenic sources as simulated by HadGEM2-A, and observed Climate Research Unit cloudiness ${ }^{15}$. b. Simulated contribution of diffuse fraction to simulated land NEE (red shadow), calculated as the difference between simulated NEE under varying diffuse fraction (black line, total NEE) minus simulated NEE under constant diffuse fraction, and simulated contribution of total PAR to simulated land NEE (green line). c. Simulated percentage change in diffuse fraction from 1950 to 1980. d. Simulated change in diffuse fraction contribution to land carbon accumulation from 1950-1980 [ $\left.\mathrm{g} \mathrm{C} \mathrm{m}^{-2} \mathrm{year}^{-1}\right]$.

Figure 4. Historical and 21st Century projections (according to the Ensembles A1B 450 stabilization scenario). a. Prescribed atmospheric $\mathrm{CO}_{2}$ (black line) and aerosol optical depth (red line). b. Simulated contribution of diffuse fraction variations (red shadow) to the cumulative land carbon sink (black line) over the 1900-2100 period. In this scenario, future climate change for the $21^{\text {st }}$ century was not considered, and climate variables, including cloud cover, were taken as fixed at their year 1999 values throughout the $21^{\text {st }}$ century simulation. 


\section{Methods}

Shortwave and PAR fields. Geographical distributions of the downward direct and diffuse radiative fluxes throughout the $20^{\text {th }}$ and $21^{\text {st }}$ centuries were obtained using look-up tables of radiative transfer calculations driven by distributions of clouds and aerosols. Aerosol distributions were simulated by the atmospheric component of the Hadley Centre Global Environmental Model version 2 (HadGEM2-A) ${ }^{16}$, which includes six tropospheric aerosol species (sulphate, black-carbon, mineral dust, sea-salt and biomass-burning). Model evaluation against ground-based Sun-photometer measurements shows model underestimation of AOD over Europe and North America in winter and north-western Africa during mineral dust and biomass-burning events. However, simulations are good during summer and throughout the year in Asia, southern Africa, and South America ${ }^{16}$.

Changes in aerosol optical depth throughout the $20^{\text {th }}$ century were obtained by varying emissions of aerosols and their precursors. Distributions of tropospheric aerosol optical depths for the six aerosol species were provided at a resolution of $1.25^{\circ}$ latitude by $1.875^{\circ}$ longitude as monthly means every ten years from 1900 to 1980, and every five years from 1980 to 2000 . Monthly distributions for the years in between were linearly interpolated from the modelled distributions. Distributions of stratospheric aerosols from the $20^{\text {th }}$ century were taken as zonal means from ref. 17.

Aerosol optical depth distributions for sulphate and black-carbon in the $21^{\text {st }}$ century were obtained by scaling the distributions for the year 2000 according to changes in the ammonium sulphate burden simulated by a chemistry-climate model using the ENSEMBLES A1B 450 scenario relying on the A1B storyline and the methodology from ref. 18. The four other 
tropospheric aerosol species, and stratospheric aerosols, were left unchanged at their 2000 levels, as their future evolution is uncertain.

Radiative transfer calculations. Downward direct and diffuse radiative fluxes were obtained independently for the clear-sky (cloud-free) and cloudy part of each gridbox. These fluxes were pre-computed and stored in look-up tables for the shortwave $(0.28$ to $4.0 \mu \mathrm{m})$ and PAR $(0.40$ to $0.69 \mu \mathrm{m})$ spectra.

In clear-sky conditions, downward direct and diffuse radiative fluxes depend on the solar zenith angle, the type and optical depth of the tropospheric aerosol, and the optical depth of the stratospheric aerosol. Aerosol phase function and scattering and absorption coefficients were computed for all aerosol species at 24 wavelengths using Mie calculations. The computed aerosol optical properties were used in a discrete-ordinate solver ${ }^{31}$ to obtain radiative fluxes. Tropospheric aerosols were assumed to be homogeneously distributed across the lowest kilometre of the atmosphere, while stratospheric aerosols reside in a homogeneous layer between 15 and $20 \mathrm{~km}$.

In cloudy sky conditions, the cloud type and optical thickness were not given by the Climate Research Unit dataset $(\mathrm{CRU})^{15}$. The only characterisation of clouds in the CRU dataset is their fractional cover, which contains little information to determine downward shortwave and PAR fluxes. To circumvent this issue, quadratic relationships between cloud cover and atmospheric transmission were derived from simulations by HadGEM2-A over each continent, on a monthly basis. Here, the atmospheric transmission is the ratio between the downward shortwave flux at the surface and the incoming shortwave flux at the top of the atmosphere. Using this ratio, the diurnal cycle of incoming shortwave flux was imposed on the downward flux at the surface. 
These relationships thus provided a means of reproducing the monthly-averaged downward flux simulated by the climate model but using the observed CRU cloud cover dataset as an input. The downward flux in the cloudy fraction of a gridbox was assumed to be purely diffuse, which is a good approximation except at very low cloud optical depth. Fluxes in the PAR spectral bands were obtained by assuming that cloud extinction was constant throughout the shortwave spectrum. Under this assumption, PAR fluxes are $41 \%$ of shortwave fluxes. A comparison of simulated total shortwave flux and diffuse fraction against ground based observations (Fig S6 and S7), allowed us to adjust the cloudy-sky flux look-up table, with a reduction of $25 \%$ of the fluxes in order to retain the set of parameters that fit best the observed fluxes.

The clear-sky flux in a given grid-box at a given time and date was obtained from the look-up table record corresponding to the current solar zenith angle, and tropospheric and stratospheric aerosol optical depths. Since look-up tables did not include combinations of different tropospheric aerosol types, the whole tropospheric column was assumed to have the optical properties of the dominant aerosol. Look-up table fluxes were linearly interpolated in solar zenith angle and tropospheric aerosol optical depth. The reconstructed clear-sky surface fluxes compared very well against those computed in HadGEM2-A. The cloudy-sky flux was derived from the value of the cloud cover in the grid-box, while the solar zenith angle determined the incoming solar radiation. Finally, cloudy- and clear-sky fluxes were weighted by the cloud cover and the clear-sky fractions, respectively, to obtain the grid-box averaged downward direct and diffuse fluxes in the shortwave and PAR spectra.

JULES evaluation at single sites. Evaluation of JULES was carried-out using hourly values of eddy correlation flux data and meteorology from two german sites: a temperate broadleaf forest 
site (Hainich) ${ }^{12}$ and a temperate needleleaf forest site (Wetzstein) ${ }^{13}$ during the summer. Meteorological forcing and diffuse radiation measured in parallel with the eddy correlation fluxes were used to force the model. To evaluate the global model at individual flux sites we calibrated model parameters to fit local ecological conditions. In particular, the model parameter that represents the maximum photosynthetic capacity, $\mathrm{V}_{\max }$, was set at 60 and $40 \mu \mathrm{mol} \mathrm{m} \mathrm{m}^{-2} \mathrm{~s}^{-1}$ for the broadleaf and needleleaf sites respectively. The corresponding values used in the global model were 32 and $24 \mu \mathrm{mol} \mathrm{m} \mathrm{m}^{-2} \mathrm{~s}^{-1}$.

Vegetation cover was updated using the TRIFFID dynamic global vegetation model, which includes a rudimentary model of leaf phenology based on growing degree days. Changes in land-use were neglected, instead a fixed land-use mask was prescribed to account for presentday crop and pasture lands. FluxNet. Computers \& Geosciences 24 (5), 443 (1998). 


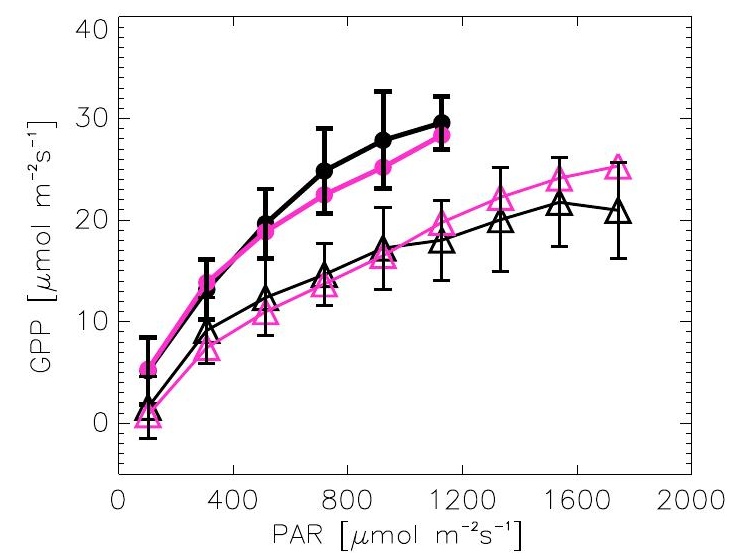




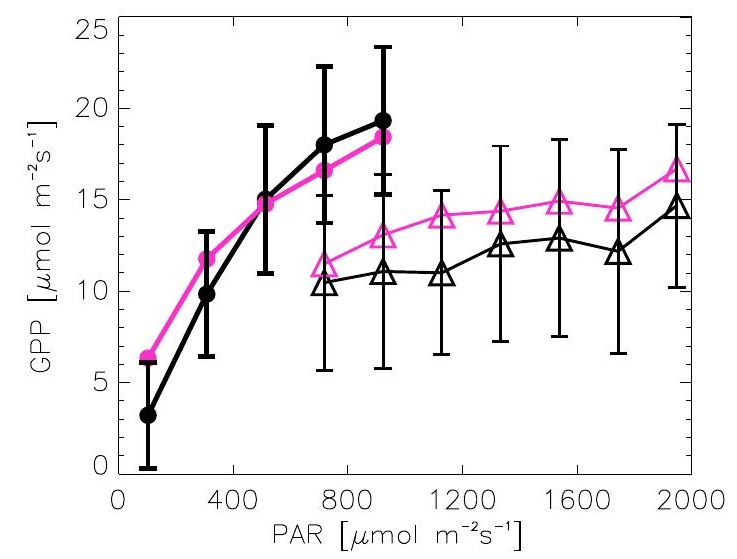



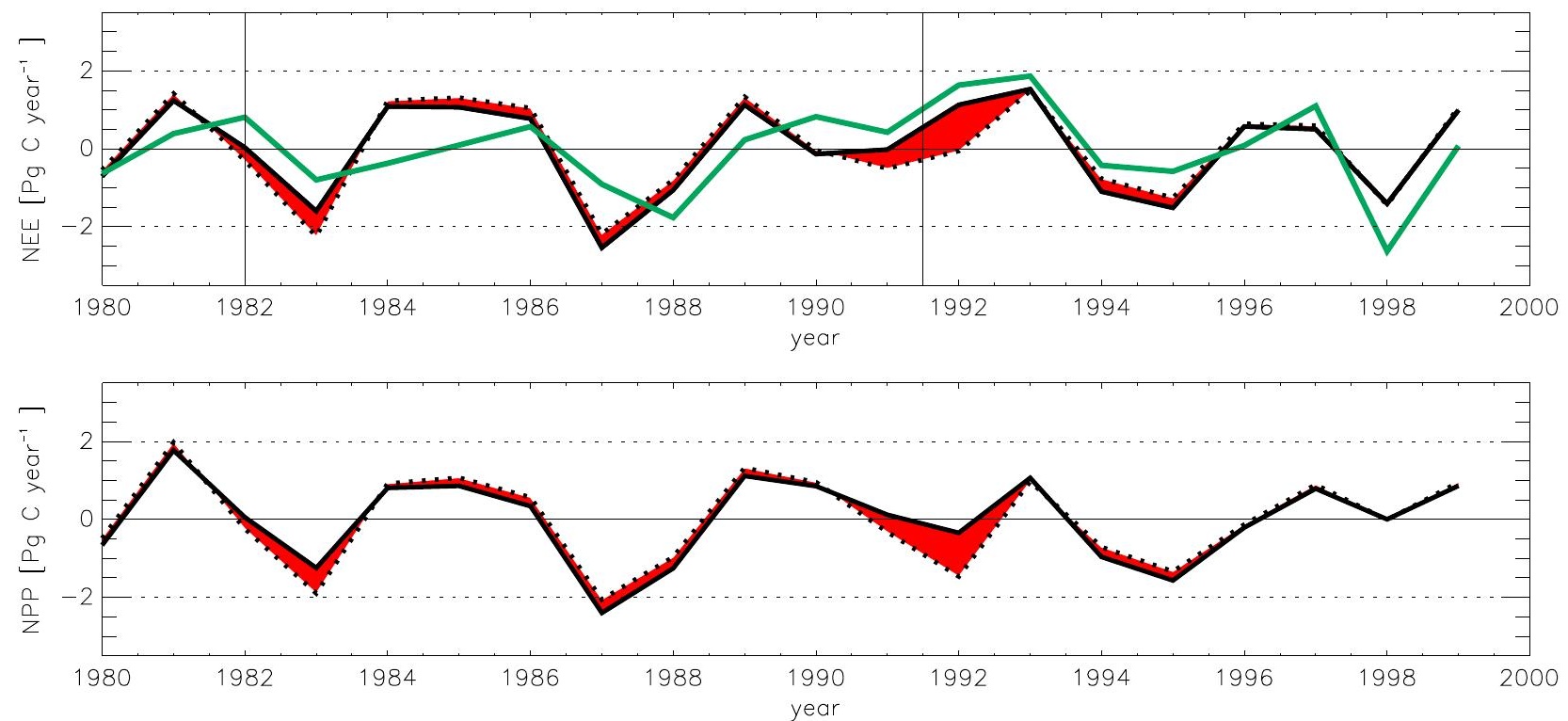
<smiles>[SiH2][SiH2][SiH2][SiH3]</smiles>

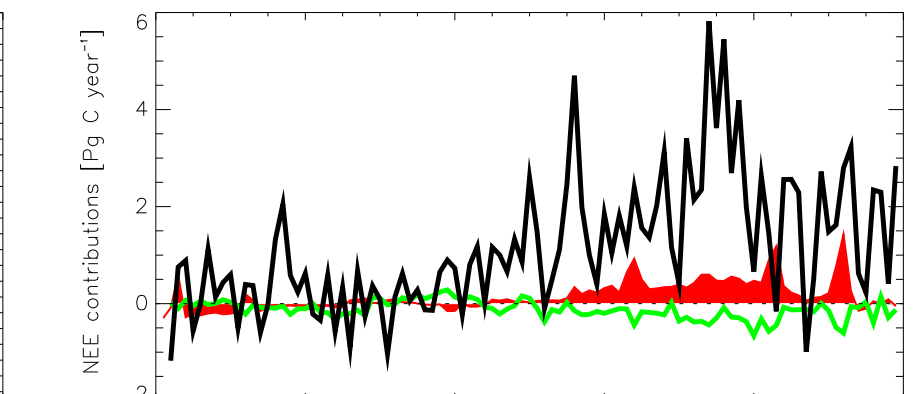




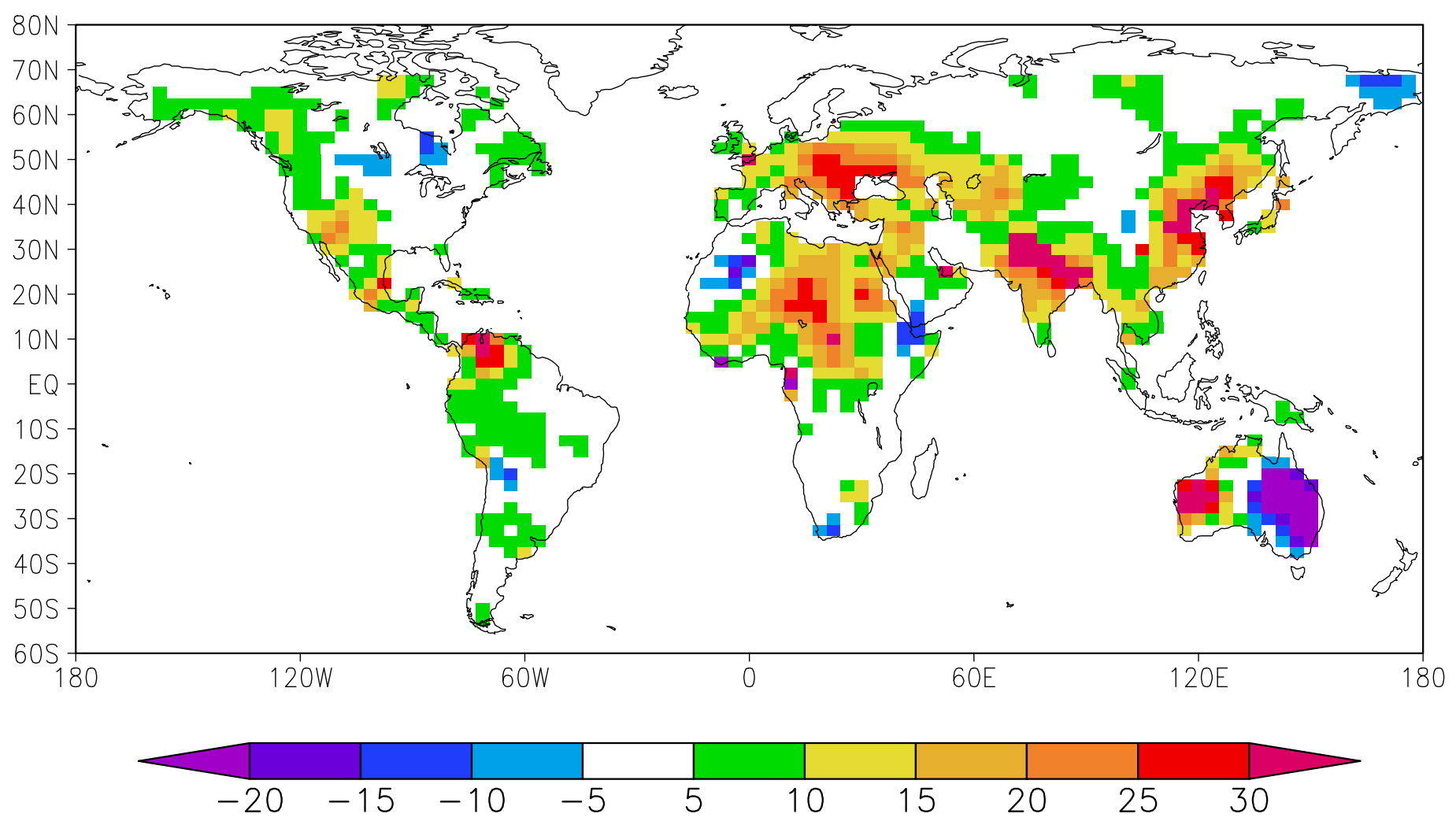




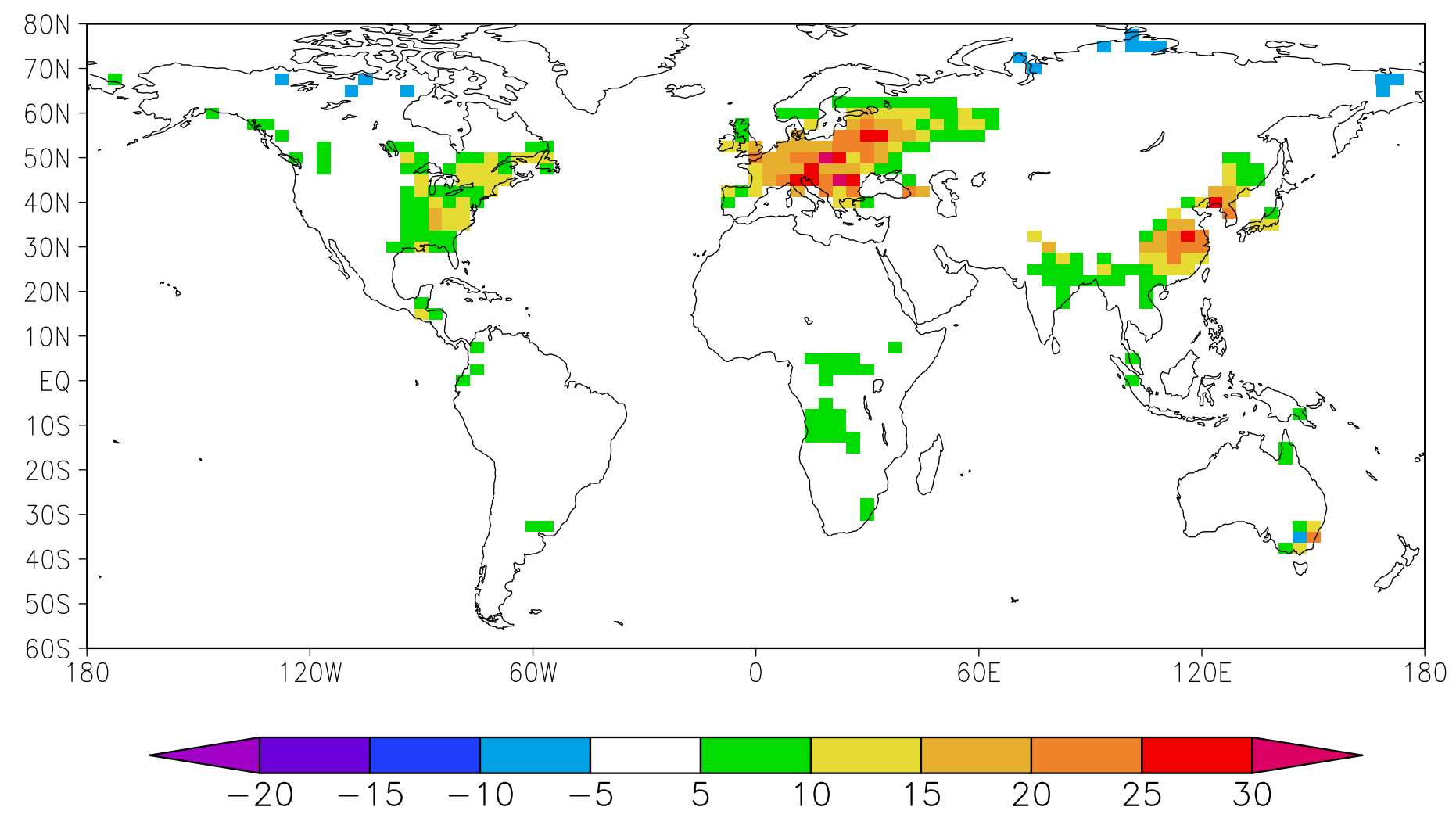



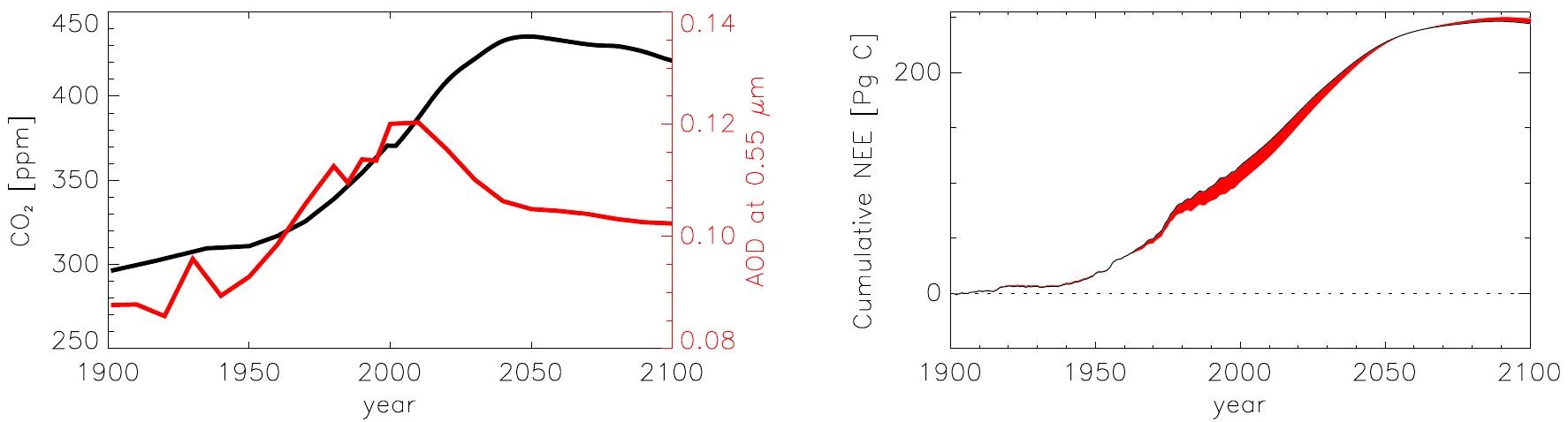